\title{
KOMUNIKASI ORGANISASI NAHDLATUL ULAMA (Studi Kasus Tentang Komunikasi Internal Pada Organisasi Pengurus Wilayah Nahdlatul Ulama Jawa Barat)
}

\section{Faisal Muzzammil}

Sekolah Tinggi Agama Islam DR. KHEZ. Muttaqien Purwakarta

E-mail: faisalzammil@gmail.com

\begin{abstract}
Pengurus Wilayah Nahdlatul Ulama (PWNU) Jawa Barat is the organizational structure of Nahdlatul Ulama (NU) at the West Java Province level, has a level of management and composition of management that is complex and different from organizations in general. The research to find out the dimensions of internal communication and the type of internal communication. This research is based on the study of internal communication in organizational communication according to Onong Uchjana Effendy.

Keywords: organizational, internal communication, PWNU Jawa Barat
\end{abstract}

\begin{abstract}
Abstrak
Pengurus Wilayah Nahdlatul Ulama (PWNU) Jawa Barat merupakan struktur organisasi NU di tingkat Provinsi Jawa Barat. PWNU Jawa Barat ini memiliki tingkatan kepengurusan dan susunan kepengurusan yang kompleks serta berbeda dengan organisasi pada umumnya. Penelitian tentang komunikasi internal pada organisasi PWNU Jawa Barat ini bertujuan untuk mengetahui: dimensi komunikasi internal pada PWNU Jawa Barat dan jenis komunikasi internal pada PWNU Jawa Barat. Penelitian ini berlandaskan pada kajian komunikasi internal dalam komunikasi organisasi menurut Onong Uchjana Effendy.
\end{abstract}

Kata Kunci: Organisasi; Komunikasi Interal; PWNU Jawa Barat

\section{PENDAHULUAN}

Pengurus Wilayah Nahdlatul Ulama (PWNU) Jawa Barat merupakan salah satu organisasi cabang pengurus NU di tingkat provinsi. Terkait dengan organisasi PWNU Jawa Barat tersebut, dalam konteks komunikasi organisasi ada beberapa entitas yang menarik dan penting untuk diteliti. Internal organisasi NU sendiri terdiri dari beberapa tingkatan kepengurusan, susunan kepengurusan dan perangkat organisasi, untuk tingkatan kepengurusan dari pusat sampai ke anak ranting, untuk susuanan kepengurusannya yakni Mustasyar, Syuriyah, dan Tanfidziyah, sedangkan untuk perangkat organisasi yaitu Lembaga, Lajnah, dan Badan Otonom. Tingkat kepengurusan, susunan kepengerusan dan beberapa perangkat organisasi tersebutlah 
yang membuat organisasi NU berbeda dengan organisasi yang lain, termasuk juga untuk PWNU Jawa Barat sebagai organisasi Nahdlatul Ulama (NU) di tingkat provinsi. ${ }^{1}$

$\mathrm{NU}$ merupakan organisasi yang unik dan cukup complex dalam tingkatan dan susunan kepengurusannya. PWNU Jawa Barat memiliki susunan kepengurusan yang secara internal terdiri dari: 1) Musytasyar Pengurus Wilayah, 2) Pengurus Wilayah Harian Syuriyah, 3) Pengurus Lengkap Syuriyah, 4) Pengurus Wilayah Harian Tandfidziyah, 5) Pengurus Wilayah Lengkap Tanfidziyah, dan 6) Pengurus Wilayah Pleno, ${ }^{2}$ selain susunan kepengurusan tersebut, PWNU Jawa Barat juga mempunyai perangkat keorganisasian NU yang terdiri dari Lembaga, Lajnah dan Badan Otonom. Berdasarkan tingkat kepengurusannya, PWNU Jawa Barat ini berada di bawah PBNU dan berada di atas PCNU Wilayah Jawa Barat. $^{3}$

Terdapat dua jalur komunikasi secara internal pada kepengurusan PWNU Jawa Barat yang saling berhubungan, jalur pertama berhubungan secara vertikal yang terjadi diantara PWNU Jawa Barat dengan PBNU dan PCNU Wilayah Jawa Barat dan jalur kedua berhubungan secara horizontal yang terjadi diantara pengurus PWNU Jawa Barat. Moedjiono Imam menyatakan bahwa setiap organisasi pada dasarnya harus mempunyai dua prinsip yang tidak boleh dilupakan, yaitu bertahan (survive) dan berkembang (develop). ${ }^{4}$ Organisasi tidak akan bertahan lama (survive) dan berkembang (develop) apabila di dalamnya tidak terjadi proses komunikasi dan interaksi baik secara vertikal dan horizontal. Mengacu pada apa yang dinyatakan oleh Moedjiono Imam, bahwa setiap organisasi apapun harus ada proses komunikasi dan interakasi di dalamnya, agar organisasi tersebut tetap bisa bertahan dan berkembang, termasuk juga PWNU Jawa Barat.

Onong Uchjana Effendy membagi proses komunikasi yang terjadi dalam lingkungan organisasi menjadi dua bagian, yaitu komunikasi internal dan komunikasi eksternal. Komunikasi internal dalam suatu organisasi terdiri dari: Pertama, dimensi komunikasi internal (meliputi komunikasi vertikal dan komunikasi horizontal). Kedua,jenis komunikasi internal (meliputi komunikasi persona dan komunikasi kelompok); sedangkan untuk komunikasi eksternal dalam suatu organisasi terbagi

${ }^{1}$ Hasil Wawancara pada Tanggal 23 September 2015 di Kantor PWNU Jawa Barat, Jl. Terusan Galunggung No. 9 Bandung.

2Pengurus Wilayah Nahdlatul Ulama Jawa Barat, Angaran Dasar \& Angaran Rumah Tangga, 11.

${ }^{3}$ Pengurus Wilayah Nahdlatul Ulama Jawa Barat, Angaran Dasar \& Angaran Rumah Tangga, 32.

${ }^{4}$ Moedjiono Imam, Kepemimpinan dan Keorganisasian, (Yogyakarta: UII Press, 2002), 135.

Vol. 3, No. 1, Juni 2020, pp 51-63 
menjadi dua, yakni komunikasi dari organisasi kepada khalayak dan komunikasi dari khalayak kepada organisasi. ${ }^{5}$

\section{PEMBAHASAN}

\section{Dimensi Komunikasi Internal pada PWNU Jawa Barat}

Menurut keterangan yang diperoleh dari Kepala Staff Sekretariat PWNU Jawa Barat, bahwa secara hirarkis Lembaga dan Lajnah PWNU Jawa Barat itu di bawah susunan Kepengurusan PWNU Jawa Barat, namun dalam proses komunikasi organisasinya bisa bersifat vertikal maupun horizontal, tergantung pada konteks tata hubungan organisasi yang digunakannnya, apakah koordinatif, informatif, atau konsultatif, dan tergantung tingkat kepengurusan dalam berkomunikasinya. ${ }^{6}$ Proses komunikasi dalam organisasi PWNU Jawa Barat yang menggunakan hubungan koordinatif atau konsultatif, maka bentuk komunikasi tersebut merupakan komunikasi vertikal; sedangkan jika ada proses komunikasi dalam PWNU Jawa Barat yang menggunakan hubungan informatif, maka bentuk komunikasi tersebut merupakan komunikasi horizontal.

\section{a. Komunikasi Vertikal dalam PWNU Jawa Barat}

Komunikasi vertikal, secara teoretis didefinisikan dengan komunikasi yang berlangusng dari atas ke bawah, dan komunikasi yang berlangsung dari bawah ke atas, atau dari segi hieraki keorganisasian komunikasi vertikal adalah komunikasi dari pimpinan ke bawahan, dan dari bawahan ke pimpinan secara timbal balik.Komunikasi dua arah secara timbal balik tersebut, dalam organisasi merupakan hal yang penting, karena jika hanya satu arah saja dari pimpinan kepada bawahan (atau sebaliknya), maka roda organisasi tidak akan berjalan dengan baik. Pimpinan organisasi perlu mengetahui laporan, tanggapan, atau saran para anggota organisasi sehingga suatu keputusan atau kebijakan dapat diambil dalam rangka mencapai tujuan yang telah ditetapkan.

Berdasarkan definisinya, komunikasi vertikal dalam suatu organisasi ini terdiri dari dua arah komunikasi, yaitu komunikasi dari atas ke bawah, dan komunikasi dari bawah ke atas. Dua arah komunikasi vertikal ini, digunakan dan diterapkan juga dalam proses komunikasi pada kehidupan organisasi di Pengurus Wilayah Nahdlatul Ulama (PWNU) Jawa Barat.Praktik komunikasi vertikal dalam PWNU Jawa Barat ini, secara umum terjadi ketika ada proses komunikasi dari tingkatan Pengurus atau susunan

\footnotetext{
5 Onong Uchjana Effendy, Ilmu Komunikasi: Teori dan Praktek, (Bandung: Remaja Rosdakarya, 2009), 122-129. ${ }^{6}$ Hasil Wawancara dengan pada Tanggal 9 Pebruari 2016 di Kantor PWNU Jawa Barat, Jl. Terusan Galunggung No. 9 Bandung.
}

Vol. 3, No. 1, Juni 2020, pp 51-63 
Pengurus yang posisinya lebih tinggi kepada Pengurus lain yang posisinya di bawah Pengurus yang lebih tinggi tadi, ataupun sebaliknya. Proses komunikasi tersebut, merupakan realitasnya nyata dari komunikasi vertikal yang ada dalam organisasi PWNU Jawa Barat.

Jika proses komunikasi dalam PWNU Jawa Barat terjadi dari Pengurus yang posisi dalam tingkatan dan susunannya lebih tinggi, kepada Pengurus yang posisi dalam tingkatan atau susunannya di bawah, maka itu merupakan komunikasi dari atas ke bawah (downward communication); sedangkan jika proses komunikasinya terjadi dari Pengurus yang di bawah, kepada Pengurus yang lebih tinggi secara struktur tingkatan atau susunanya, maka itu merupakan komunikasi dari bawah ke atas (upward communication).Fakta tentang praktik komunikasi ke bawah (downward communication) dan komunikasi ke atas (upward communication) dalam organisasi PWNU Jawa Barat ini, diperoleh dari hasil observasi dan penelitian yang dilakukan di Kantor PWNU Jawa Barat, secara skematis dapat digambarkan dengan kerangka seperti berikut:

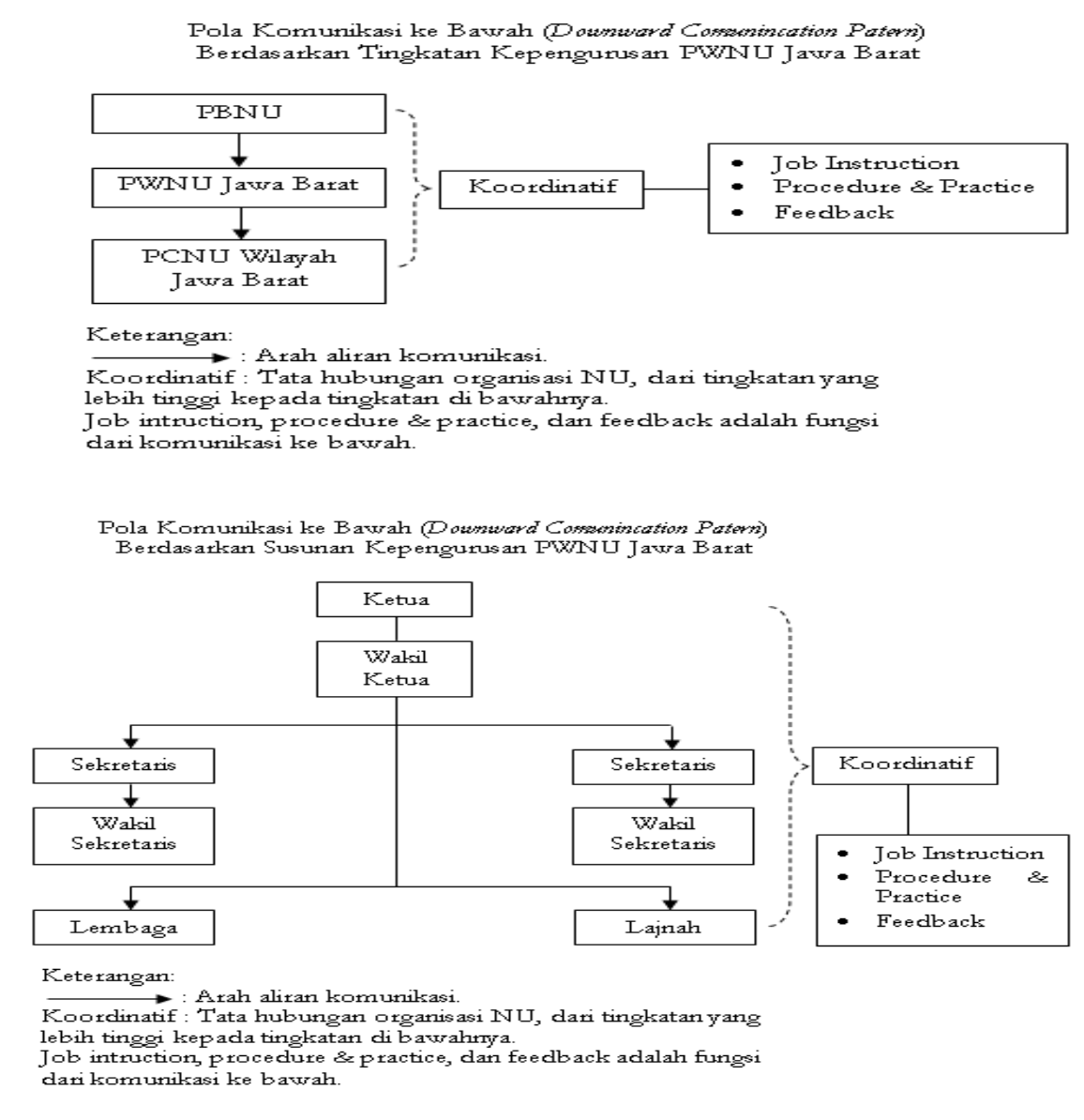

Gambar 1. Downward Communication PWNU Jawa Barat (Lanjutan)

Vol. 3, No. 1, Juni 2020, pp 51-63

Faisal

Komunikasi Organisasi Nahdlatul Ulama... 
Komunikasi ke bawah dalam PWNU Jawa Barat sekurang-kurangnya memiliki tiga fungsi, yaitu jobs intstruction, procedure and practice, dan feedback.Pertama, komunikasi ke bawah dalam PWNU Jawa Barat berfungsi sebagai jobs intruction. Jobs intructions sendiri adalah suatu informasi mengenai bagaimana melakukan pekerjaan. Seperti yang telah dicontoh sebelumnya, bahwa jika PWNU Jawa Barat akan mengadakan suatu kegiatan dalam bidang tertentu, maka Tanfidziyah menginstruksikan kepada Lembaga terkait untuk melaksanakan kegiatan tersebut. Intruksi tersebut biasanya berisi tentang rancangan, prosedur, dan teknis kegiatan yang akan dilaksanakan.

Kedua, komunikasi ke bawah dalam PWNU Jawa Barat berfungsi sebagai procedure and practice. Procedure and practice adalah suatu informasi mengenai kebijakan dan praktik pengembangan organisasi. Komunikasi ke bawah dalam fungsi ini biasanya berisi informasi yang bersifat keorganisasian, seperti realisasi program kerja, evaluasi kinerja organisasi, dan usaha-usaha untuk mengembangkan keorganisasian agar lebih dinamis.

Ketiga, komunikasi ke bawah dalam PWNU Jawa Barat berfungsi sebagai feedback. Feedback adalah suatu informasi mengenai kinerja pegawai. Sama seperti yang telah dibahas sebelumnya, fungsi feedback dalam komunikasi ke bawah dalam PWNU Jawa Barat ini dilakukan dengan cara rapat koordinasi dengan mengundang Pengurus Lembaga untuk berdiskusi dan menerima laporan hasil kinerjanya. Komunikasi ke bawah ini merupakan media untuk menerima laporan (feedback) dari Pengurus yang lebih rendah kepada Pengurus yang lebih tinggi, baik dari segi tingkatan kepengurusan atau susunan kepengurusannya.

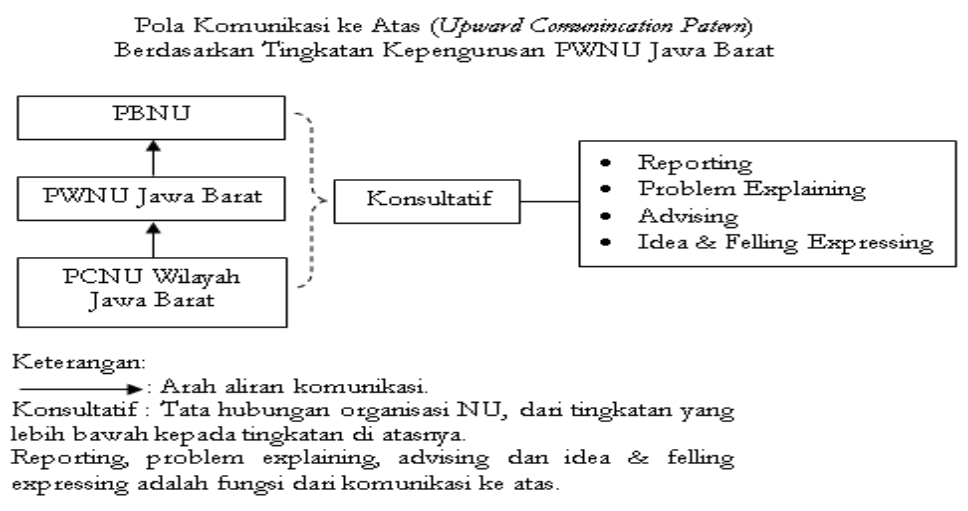

Gambar 2. Upward Communication PWNU Jawa Barat

Vol. 3, No. 1, Juni 2020, pp 51-63

Faisal

Komunikasi Organisasi Nahdlatul Ulama... 


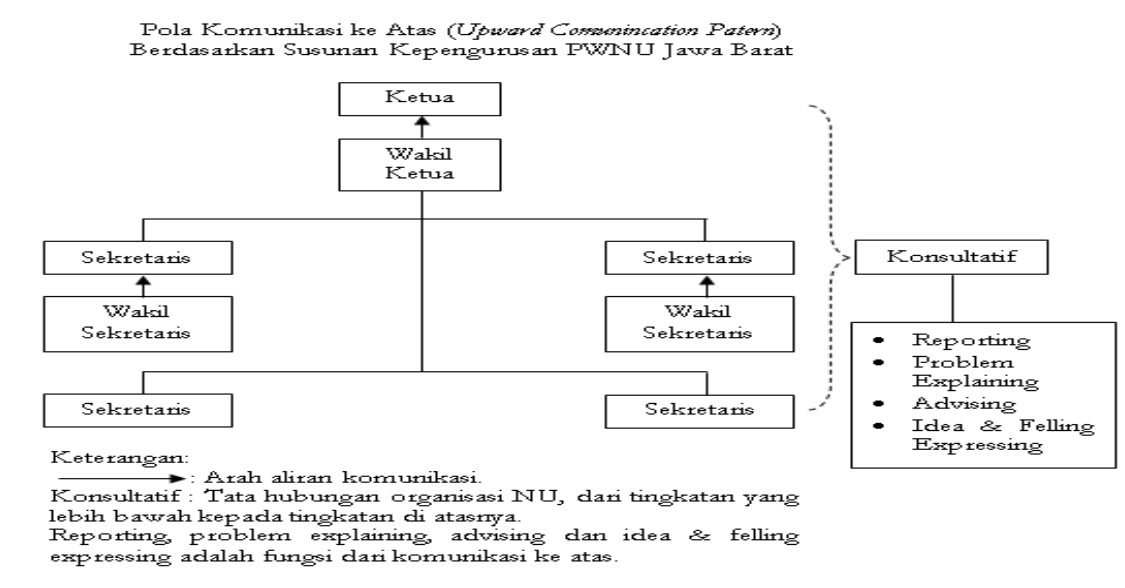

Gambar 2. Upward Communication PWNU Jawa Barat (Lanjutan)

Komunikasi ke atas dalam PWNU Jawa Barat berfungsi sebagai: Pertama, memberitahukan apa yang dilakukan bawahan. Fungsi ini jelas sekali dalam proses komunikasi ke atas, seperti yang telah diuraikan sebelumnya, bahwa contoh nyata dari fungsi ini adalah laporan kinerja dari PWNU kepada PBNU, dari Tanfidziyah kepada Syuriah, dan dari PCNU Wilayah Jawa Barat kepada PWNU Jawa Barat. Laporan tersebut pada dasarnya adalah pemberitahuan dari bawahan kepada atasan tentang apa saja program kerja atau kebijakan organisasi yang telah direalisasikannya. Fungsi pertama ini biasanya disebut dengan istilah reporting.

Kedua, menjelaskan persoalan-persoalan kerja yang belum dipecahkan. Komunikasi ke atas dalam PWNU Jawa Barat ini berfungsi sebagai wadah konsultasi bagi Lembaga atau Lajnah untuk menyampaikan permasalahan kepada Tanfidziyah, misalnya ada beberapa program kerja yang belum direalisasikan oleh Lembaga atau Lajnah. Komunikasi ke atas ini menjadi sarana konsultasi bagi unit organisasi yang berada di bawah kepada unit yang lebih tinggi kedudukannya. Konsultasi tentang persoalan keorganisasian ini juga dilakukan dari PWNU kepada PBNU, dan dari PCNU kepada PWNU. Fungsi ini juga sesuai dengan tata hubungan organisasi yang ada pada PWNU Jawa Barat, yaitu hubungan konsultatif. Fungsi ini sering disebut juga dengan istilah problem explaining.

Ketiga, memberikan saran atau gagasan dalam rangka pengembangan organisasi. Lembaga atau Lajnah biasanya sering memberikan saran dan arahan kepada Tanfidziyah untuk tujuan pengembangan kemajuan organisasi PWNU Jawa Barat. Tanfidziyah kemudian menyalurkan aspirasi dari Lembaga atau Lajnah tersebut kepada Syuriah. Melalui rapat pleno atau evaluasi biasanya Pengurus PWNU Jawa

Vol. 3, No. 1, Juni 2020, pp 51-63 
Barat yang berada di bawah bisa memberikan saran dan masukan kepada tingkatan yang di atasnya untuk pengembangan dan kemajuan organisasi NU diwilayah Jawa Barat. Memberikan saran dan gagasan juga sering dilakukan dari PWNU kepada PBNU, dan dari PCNU kepada PWNU Bahasa lain untuk menyebut fungsi yang ketiga ini, biasanya menggunakan istilah advising.

Keempat, mengungkapkan pikiran dan perasaan baik mengenai pekerjaan maupun keorganisasian. Komunikasi ke atas dalam PWNU Jawa Barat ini, selain digunakan sebagai sarana konsultasi pemecahan masalah dan memberikan saran bagi kemajuan organisasi, juga digunakan sebagai sarana untuk mengeluarkan uneguneg yang dialami oleh para Pengurus, baik dalam masalah program kerja, kebijakan organisasi, maupun rekan sesama Pengurus. Fungsi keempat dari komunikasi ke atas ini, dapat juga dilakukan dari PWNU kepada PBNU dan dari PCNU kepada PWNU. Istilah lain yang digunakan untuk fungsi keempat ini adalah idea and felling expressing.

\section{b. Komunikasi Horizontal pada PWNU Jawa Barat}

Komunikasi horizontal, secara teknis adalah tindakan komunikasi yang berlangsung di antara para anggota organisasi atau bagian yang memiliki keududukan yang sama. Kedudukan komunikasi horizontal ini menjadi penting dalam kehidupan organisasi, karena secara teoretis menurut Phillip V. Lewis, komunikasi horizontal dalam praktiknya adalah $67 \%$ dari seluruh komunikasi yang ada dalam kehidupan organisasi. $^{7}$

Komunikasi horizontal ini, jika ditinjau dari perspektif tata hubungan organisasi PWNU Jawa Barat sama dengan hubungan informartif. Hubungan informatif tersebut adalah hubungan timbal balik yang saling memberikan informasi yang diperlukan. Hubungan informatif ini sama dengan komunikasi horizontal pada dimensi internal dalam komunikasi organisasi, karena ada hubungan timbal balik antara komunikator dan komunikan yang ada dalam satu tingkatan dan memliki kedudukan yang sama, atau dalam bahasa lain hubungan informatif dan komunikasi horizontal ini sering disebut information sharing.Gerald M. Goldhaber menyatakan bahwa ada empat fungsi komunikasi horizontal dalam suatu organisasi: 1) koordinasi tugas, 2) penyelesaian masalah, 3) berbagi informasi, dan 4) penyelesaian konflik.

Realitas tentang praktik komunikasi horizontal dalam organisasi PWNU Jawa Barat ini, diperoleh dari hasil observasi dan penelitian yang dilakukan di Kantor PWNU Jawa Barat, secara skematis dapat digambarkan dengan kerangka berikut:

${ }^{7}$ Andr Hardjana, Komunikasi Organisasi: Straegi dan Kompetensi, (Jakarta: Kompas MU, 2016), 153. 


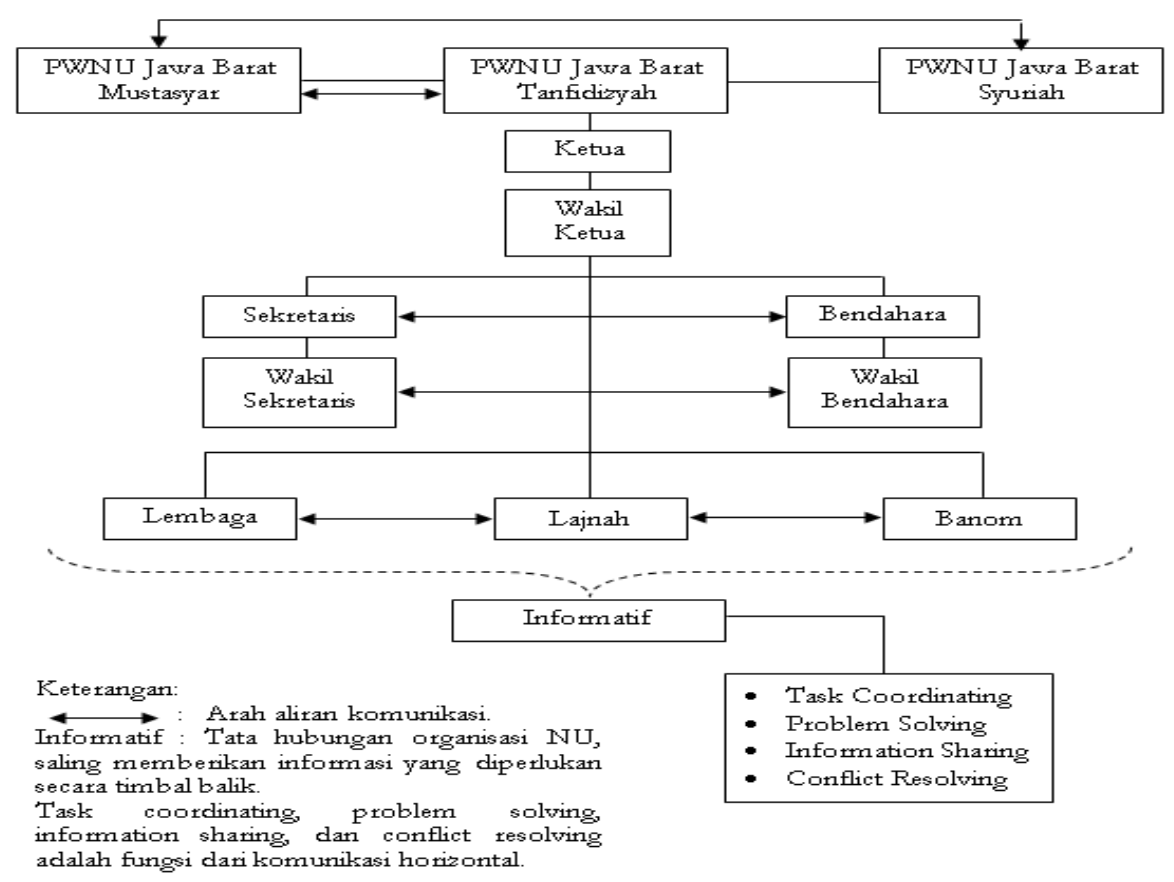

Gambar 3. Komunikasi Horizontal PWNU Jawa Barat

Komunikasi horizontal dalam PWNU Jawa Barat ini setidaknya berfungsi sebagai: koordinasi tugas, penyelesaian masalah, berbagi informasi, dan penyelesaian konflik.Pertama, komunikasi horizontal dalam PWNU Jawa Barat berfungsi sebagai koordinasi tugas. Melalui komunikasi horizontal ini, setiap komponen organisasi yang setingkat dalam PWNU Jawa Barat saling bekoordinasi dan berkomunikasi terkait kerja sama dan pembagian tugas dalam rangka merealisasikan program kerja, melaksanakan kebijakan, mengembangkan organisasi PWNU Jawa Barat. Bahasa lain untuk menyebut fungsi komunikasi horizontal yang pertama ini adalah task coordinating.

Kedua, komunikasi horizontal dalam PWNU Jawa Barat berfungsi sebagai penyelesaian masalah. Setiap ada masalah yang terjadi dalam PWNU Jawa Barat, biasanya semua komponen organisasi saling berkomunikasi dan berdiskusi untuk mencari jalan keluar (problem solving) dari permasalah tersebut. Contohnya, jika ada kebijakan dan program kerja PWNU Jawa Barat yang belum pernah terealisasi, maka komponen organisasi yang terkait akan saling berkomunikasi untuk segera merealisasikan program organisasi tersebut.

Ketiga, komunikasi horizontal dalam PWNU Jawa Barat berfungsi sebagai berbagi informasi. Fungsi ini menjadi esensi yang paling dasar dalam komunikasi horizontal pada organisasi PWNU Jawa Barat. Komunikasi horizontal pada dasarnya

Vol. 3, No. 1, Juni 2020, pp 51-63 
merupakan proses pertukaran informasi antar komponen organisasi PWNU Jawa Barat yang ada dalam satu tingkatan. Berbagi informasi ini merupakan salah satu hubungan tata organisasi yang ada dalam PWNU Jawa Barat, yaitu hubungan informatif. Fungsi komunikasi horizontal ini, biasanya sering juga disebut dengan information sharing.

Keempat, komunikasi horizontal dalam PWNU Jawa Barat berfungsi sebagai penyelesaian konflik. Konflik dalam setiap organisasi, tidak dapat dihindari dan pasti terjadi, termasuk juga dalam PWNU Jawa Barat. Komunikasi horizontal ini berfungsi untuk meminimalisir dan menyelesaikan konflik tersebut. Jika ada konflik yang terjadi dalam internal PWNU Jawa Barat, maka untuk meminimalisir dan menyelesaikannya dengan cara berkomunikasi dan berdiskusi secara horizontal antara pihak-pihak yang terlibat konflik tersebut. Penyelesain konflik, yang dapat dilakukan dengan komunikasi horizontal ini, secara lebih sederhana bisa disebut dengan conflict resolving.

\section{Jenis Komunikasi Internal pada PWNU Jawa Barat}

Jenis komunikasi internal dalam suatu organisasi dapat diklasifikasikan berdasarkan jumlah anggota organisasi yang terlibat dalam aktivitas komunikasi tersebut. Jenis komunikasi internal dalam suatu organisasi, diklasifikasikan oleh Onong Uchjana Efenddy menjadi dua, yaitu: komunikasi personal (personal communication) dan komunikasi kelompok (group communication). Komunikasi personal adalah komunikasi antara dua orang dan dapat berlangsung dengan dua cara, yaitu: komunikasi tatap muka dan komunikasi bermedia. Komunikasi personal tatap muka berlangsung secara dialogis sambil menatap sehingga terjadi kontak pribadi (personal contact), inilah yang disebut komunikasi antarpersonal (interpersonal communication). Komunikasi personal bermedia adalah komunikasi dengan menggunakan alat (media). Komunikasi kelompok adalah komunikasi antara seseorang dengan sekelompok orang dalam situasi tatap muka, kelompok ini bisa kecil, bisa juga besar. Besar atau kecilnya suatu kelompok dalam komunikasi, tidak ditentukan dengan perhitungan eksak, tapi ditentukan berdasarkan ciri dan sifat komunikan dalam hubungannya dengan proses komunikasi.

\section{a. Komunikasi Personal dalam PWNU Jawa Barat}

Wahyu Wibisana menjelaskan bahwa komunikasi personal dalam PWNU Jawa Barat terjadi antara Pengurus yang satu dengan Pengurus yang lainnya secara personal, baik itu dari Mustasyar, Syuriah, maupun Tanfidziyah. Komunikasi personal dalam PWNU Jawa Barat ini bisa terjadi pada internal komponen organisasi ataupun antar komponen organisasi, karena setiap komponen organisasi dalam PWNU Jawa

Vol. 3, No. 1, Juni 2020, pp 51-63 
Barat ini terdiri lebih dari satu orang. Maka dari itu praktik komunikasi personal dalam PWNU Jawa Barat ini sangat sering terjadi. ${ }^{8}$

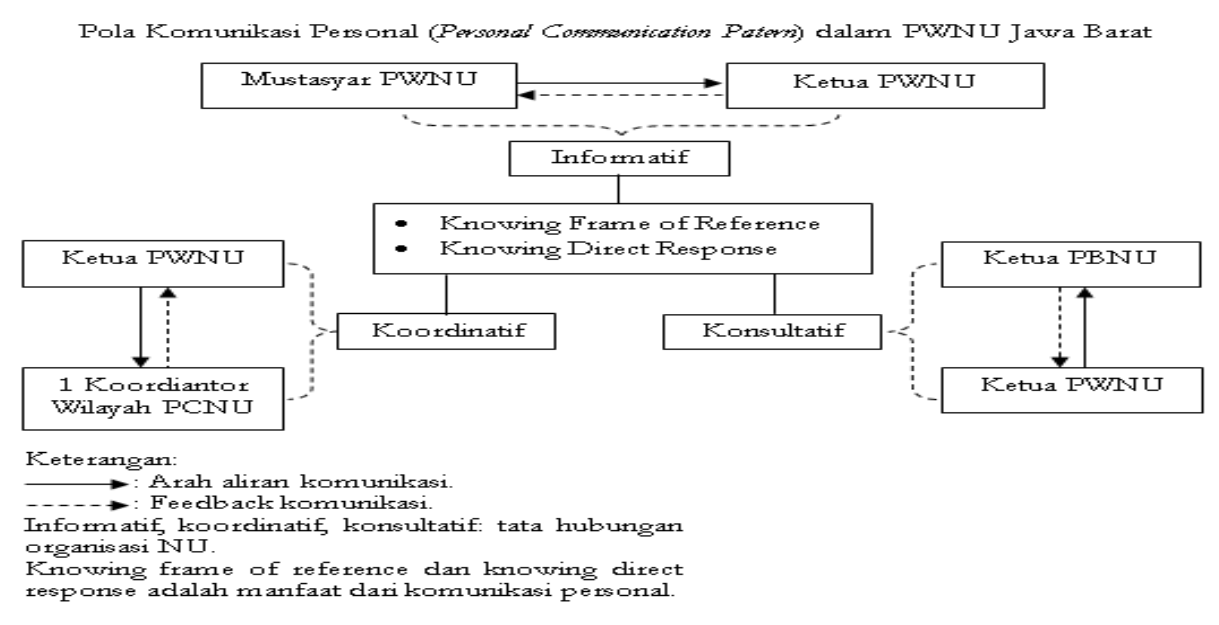

Gambar 4. Komunikasi Personal PWNU Jawa Barat

Komunikasi personal dalam PWNU Jawa Barat, setidaknya bermanfaat untuk dua hal: Pertama, mengetahui frame of reference seorang Pengurus secara personal. Kedua, mengetahui tanggapan langsung dari Pengurus pada saat berkomunikasi.Komunikasi personal dalam PWNU Jawa Barat bermanfaat untuk mengetahui frame of reference setiap Pengurus secara personal. Tingkat pemahaman, pengetahuan, perilaku organisasi, dan pola pikir dari seorang Pengurus akan dapat diketahui dengan melakukan komunikasi secara personal dengan Pengurus tersebut (knowing frame of reference). Komunikasi personal dalam PWNU Jawa Barat bermanfaat untuk mengetahui tanggapan (respons, feedback) dari setiap Pengurus secara langsung. Tanggapan atau respons dari seorang Pengurus tentang berbagai hal yang berkaitan dengan organisasi akan dapat diketahui secara langsung dengan melakukan komunikasi secara personal (knowing direct response).

\section{b. Komunikasi Kelompok dalam PWNU Jawa Barat}

Pratik komunikasi dalam PWNU Jawa Barat bisa dibagi menjadi tiga jenis, yakni komunikasi dari seorang Pengurus kepada kelompok Pengurus, komunikasi dari kelompok Pengurus kepada seorang Pengurus, dan komunikasi dari kelompok Penguus kepada kelompok Pengurus lain.Tiga jenis praktik komunikasi kelompok tersebut terjadi dalam internal PWNU Jawa Barat. Secara lebih jelas, contoh tiga jenis

${ }^{8}$ Hasil Wawancara dengan pada Tanggal 11 Pebruari 2016 di Kantor PWNU Jawa Barat, Jl. Terusan Galunggung No. 9 Bandung.

Vol. 3, No. 1, Juni 2020, pp 51-63 
praktik komunikasi kelompok dalam organisasi PWNU Jawa Barat tersebut, diskemakan seperti berikut:

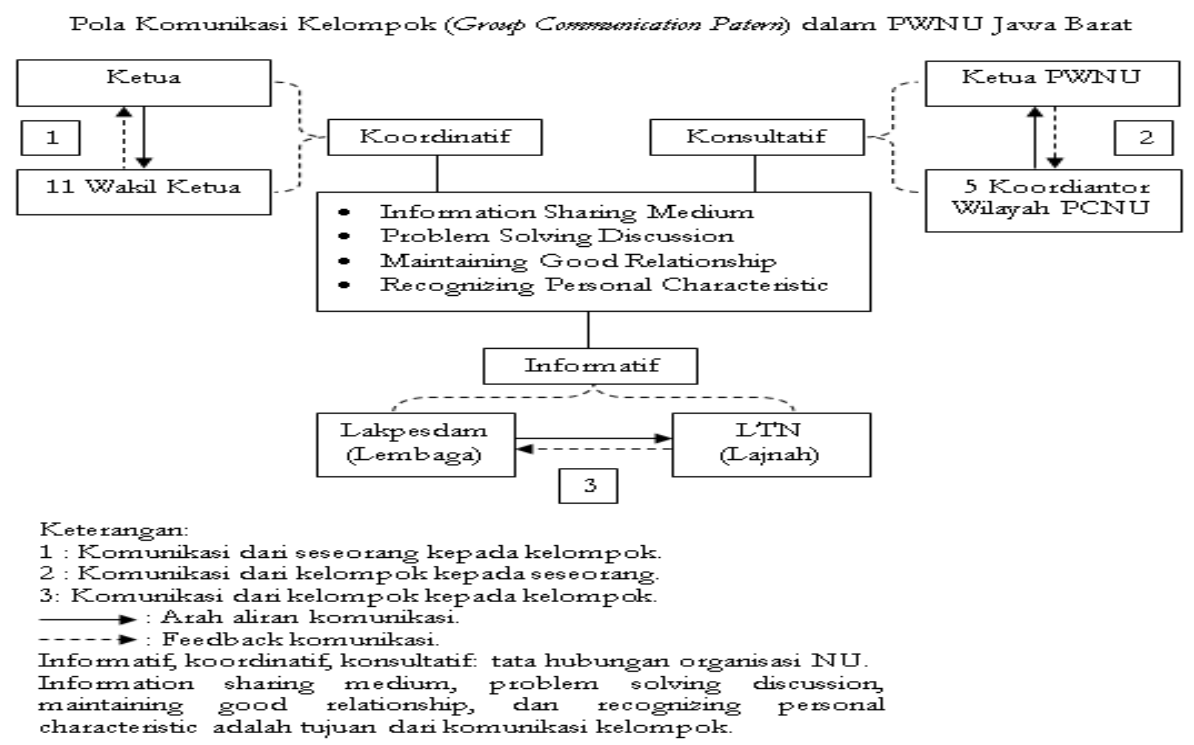

Gambar 5. Komunikasi Horizontal PWNU Jawa Barat

Komunikasi kelompok dalam PWNU Jawa Barat memiliki tujuan sebagai berikut:Pertama, sarana berbagi infomasi. Tujuan utama dalam komunikasi, pada dasarnya adalah berbagi informasi. Seseorang berkomunikasi dengan orang lain pada dasarnya untuk membagi dan memenuhi kebutuhan informasi, maka dari itu komunikasi kelompok ini menjadi sangat penting sebagai sarana pemenuhan kebutuhan informasi dalam sebuah kelompok dalam suatu organisasi, termasuk juga dalam organisasi PWNU Jawa Barat. Istilah lain untuk menyebut tujuan yang pertama ini adalah information sharing medium.

Kedua, diskusi untuk memecahkan suatu masalah. Komunikasi kelompok ini dirasa efektif untuk melakukan diskusi dan membahas suatu permasalahan yang membutuhkan penyelesaian. Melalui komunikasi kelompok ini, para Pengurus dapat bertukar ide dan gagasan untuk membahas dan menemukan penyelesaian dari suatu permasalahan. Istilah lain untuk menyebut tujuan yang kedua ini adalah problem solving discussion.

Ketiga, menjaga hubungan baik antar Pengurus. Komunikasi kelompok yang dilakukan secara intensif akan dapat berpengaruh pada kedekatan antara Pengurus yang satu dengan Pengurus yang lainnya. Melalui komunikasi kelompok inilah hubungan baik antar Pengurus dapat terjaga dan terpelihara. Istilah lain untuk menyebut tujuan yang ketiga ini adalah maintaining good relationship. 
Keempat, saling mengenal karakteristik pribadi. Komunikasi kelompok yang dilakukan secara intensif, selain dapat menjaga hubungan baik, juga dapat dijadikan sarana untuk mengenal karakteristik pribadi masing-masing Pengurus. Melalui komunikasi kelompok inilah para Pengurus bisa bercerita dan bertukar pengalaman tentang kepribadian dan kehidupannya. Istilah lain untuk menyebut tujuan yang pertama ini adalah recognizing personal characteristic.

\section{PENUTUP}

Berdasarkan kesimpulan hasil penelitian tentang komunikasi internal PWNU Jawa Barat, ada tiga entitas yang disarankan dalam peneltian ini: Pertama, dari aspek teori komunikasi organisasi. Penelitian ini menggunakan beberapa teori yang berkaitan dengan berbagai kajian teori komunikasi organisasi. Teori komunikasi organisasi yang digunakan dalam penelitian ini adalah dimensi komunikasi dalam kehidupan organisasi dari Onong Uchjana Effendy, definisi komunikasi organisasi menurut Pace dan Faules, Teori Strukturasi, Teori Analisis Interaksi, dan Teori Pikiran Kelompok. Disarankan untuk melakukan penelitian komunikasi organisasi dengan berbagai teori yang lainnya.

Kedua, dari aspek praktis komunikasi organisasi PWNU Jawa Barat. Hasil penelitian tentang komunikasi internal pada PWNU Jawa Barat ini, secara praktis dapat digunakan sebagai pola komunikasi organisasi dalam suatu Lembaga Dakwah. Berdasarkan aspek praktis tersebut, disarankan bagi suatu Lembaga Dakwah untuk menggunakan pola komunikasi organisasi yang ada dalam komunikasi internal PWNU Jawa Barat.

Ketiga, dari aspek kajian dan fokus penelitian komunikasi organisasi. Penelitian yang dilakukan ini berfokus pada komunikasi internal dalam suatu organisasi, yang mengkaji tentang dimensi komunikasi internal dan jenis komunikasi internal. Disarankan untuk melakukan penelitian tentang komunikasi organisasi yang mengkaji selain komunikasi internal, misalnya penelitian tentang komunikasi eksternal dan iklim komunikasi organisasi.

\section{DAFTAR PUSTAKA}

Anwar, Rosihon. 2007. NU Jawa Barat: Sejarah dan Perkembangannya. Bandung: Sunyaragi Pranta Mandiri.

Effendy, Onong Uchjana. 2009. Ilmu Komunikasi: Teori dan Praktek. Bandung: PT Remaja Rosdakarya,

Emzir. 2012. Metode Penelitian Kualitatif: Analisis Data. Jakarta: Rajawali Pers.

Enjang AS dan Aliyudin. 2009.Dasar-Dasar IImu Dakwah: Pendekatan Filosofis \& Praktis. Bandung: Widya Padjajaran.

Fadeli, H. Soeleiman dan Mohmmmad Subhan. 2007.Antologi NU: Sejarah-IstilahAmaliah-Uswah. Surabaya: Khalista,

Vol. 3, No. 1, Juni 2020, pp 51-63

Faisal

Komunikasi Organisasi Nahdlatul Ulama... 
Hardjana, Andre. 2016.Komunikasi Organisasi: Strategi dan Kompetensi. Jakarta: PT Kompas Media Nusantara.

Herdiansyah, Haris. 2011. Metode Penelitian Kualitatif: Untuk IImu-IImu Sosial. Jakarta: Salemba Humanika.

Kholiq, Muzawwir. 2010. Pola Komunikasi Organisasi (Studi Kasus: Pola Komunikasi antara Pimpinan dan Karyawan di Radio Kota Perak Yogyakarta. Yogyakarta: UIN Sunan Kalijaga,

Kuswarno, Engkus. 2012. Fenomenologi. Bandung: Widya Padjajaran.

Lesmana (Pent). NU: Vis-aVis Negara Pencarian Isi, Bentuk dan Makna. Yogyakarta: LkiS.

Littlejohn, Stephen W. dan Karen A. Foss. 2009. Teori Komunikasi: Theories of Human Communication. Jakarta: Salemba Humanika.

Moleong, Lexy J. 1997. Metode Peneltian Kualitatif. Bandung: Rosdakarya.

Morissan. Teori Komunikasi Organisasi. Bogor: Ghalia Indonesia, 2009.

Muhamad, Billy. 2012. Komunikasi Organisasi (Studi Kasus tentang Pola Komunikasi Organisasi pada Divisi Procurement PT. Telekomunikasi Seluler Regional Jawa Barat). Bandung: Universitas Padjajaran.

Mulyana, Deddy. 2009. IImu Komunikasi: Suatu Pengantar. Bandung: PT Remaja Rosdakarya.

Nazir, Moh. 2014. Metode Penelitian. Bogor: Ghalia Indonesia..

Nurhadi, Zikri Fachrul. 2015. Teori-Teori Komunikasi: Teori Komunikasi dalam Perspektif Penelitian Kualitatif. Bogor: Ghalia Indonesia.

Pace, R. Wayne dan Don F. Faules. 2006. Komunikasi Organisasi: Strategi Meningkatkan Kinerja Perusahaan. Bandung: PT Remaja Rosdakarya.

Pengurus Wilayah Nahdlatul Ulama Jawa Barat. 2010. Anggaran Dasar \& Anggaran Rumah Tangga Nahdlatul Ulama. Bandung: LTN PWNU Jawa Barat.

Program Pascasarjana. 2014. Panduan Penulisan Tesis dan Disertasi. Bandung: UIN Sunan Gunung Djati.

Putra, Ridwan Aditya. 2013. Pola Komunikasi Organisasi Pengurus Besar Nahdlatul Ulama (PBNU). Jakarta: UIN Syarif Hidayatullah.

PWNU Jawa Barat. 2011. Hasil Konfrensi Wilayah ke-16 Nahdlatul Ulama Jawa Barat. Bandung: PWNU Jawa Barat.

PWNU Jawa Barat. 2012. Materi Musyawarah Kerja Wilayah Nahdlatul Ulama Jawa Barat. Bandung: PWNU Jawa Barat.

Rakhmat, Jalaluddin. 2012. Metode Penelitian Komunikasi: Dilengkapi Contoh Analisis Statistik. Bandung: Remaja Rosdakarya.

Rohim, H. Syaiful. 2009. Teori Komunikasi: Perspektif, Ragam, dan Aplikasi. Jakarta: PT Rineka Cipta.

Ruliana, Poppy. 2014, Komunikasi Organisasi: Teori dan Studi Kasus. Jakarta: PT Rajawali Per.

Santoso, Budi. 2008. Implementasi Komunikasi Organisasi Internal di Redaksi Majalah Fahma Yogyakarta. Yogyakarta: UIN Sunan Kalijaga.

Susilawati, Fitri. 2010. Komunikasi Organisasi dalam Kepemimpinan pada PT Tempo Inti Media. Jakarta: UIN Syarif Hidayatullah.

W. Creswell, John. 2013. Research Design: Pendekatan Kualitatif, Kuantitatif, Mixed. Yogyakarta: Pustaka Pelajar.

Yin, Robert K. 2012. Studi Kasus: Desain \& Metode. Jakarta: Rajawali Pers.

Vol. 3, No. 1, Juni 2020, pp 51-63

Faisal

Komunikasi Organisasi Nahdlatul Ulama... 